Florida International University FIU Digital Commons

\title{
The creation of guidelines on event production strategies for implementation in performing arts venues
}

Marie-Régine G. Considine
Florida International University

DOI: $10.25148 /$ etd.FI14060897

Follow this and additional works at: https://digitalcommons.fiu.edu/etd

Part of the Music Commons

\section{Recommended Citation}

Considine, Marie-Régine G., "The creation of guidelines on event production strategies for implementation in performing arts venues" (2007). FIU Electronic Theses and Dissertations. 2427.

https://digitalcommons.fiu.edu/etd/2427 
FLORIDA INTERNATIONAL UNIVERSITY

Miami, Florida

THE CREATION OF GUIDELINES ON EVENT PRODUCTION STRATEGIES FOR IMPLEMENTATION IN PERFORMING ARTS VENUES

A thesis submitted in partial fulfillment of the requirements for the degree of

MASTER OF MUSIC

by

Marie-Régine G. Considine

2007 
To: Dean Juan Antonio Bueno

College of Architecture and the Arts

This thesis, written by Marie-Régine G. Considine, and entitled The Creation of Guidelines on Event Production Strategies for Implementation in Performing Arts Venues, having been approved in respect to style and intellectual content, is referred to you for judgment.

We have read this thesis and recommend that it be approved.

Robert Dundas

Fredrick Kaufman

Karen Fuller, Major Professor

Date of Defense: March 27, 2007

The thesis of Marie-Régine G. Considine is approved.

Dean Juan Antonio Bueno College of Architecture and the Arts

Dean George Walker University Graduate School

Florida International University, 2007 


\title{
ABSTRACT OF THE THESIS \\ THE CREATION OF GUIDELINES ON EVENT PRODUCTION STRATEGIES FOR IMPLEMENTATION IN PERFORMING ARTS VENUES
}

by

\author{
Marie-Régine G. Considine
}

Florida International University, 2007

Miami, Florida

Professor Karen Fuller, Major Professor

The purpose of the research was to find the best arts management techniques for the production of live events to be developed into guidelines to assist performing arts organizations in the creation of their own production strategies.

Methodologies included consulting with theatre professionals and attending management seminars and conferences related to the field of live production. A literature review of arts management guides and books was conducted to provide the background needed to develop the strategies.

Based on the findings, guidelines were developed to assist performing arts managers in conducting a thorough analysis of their organization, deciding on the scope of a strategy, as well as implementing, evaluating and revising the strategy.

The study concluded that performing arts organizations would greatly benefit from the development and implementation of a production strategy that will improve employee performance, client satisfaction, conserve resources, and streamline live events. 


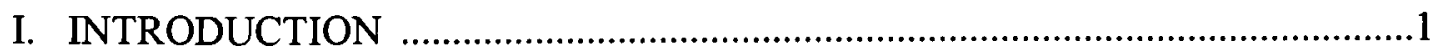

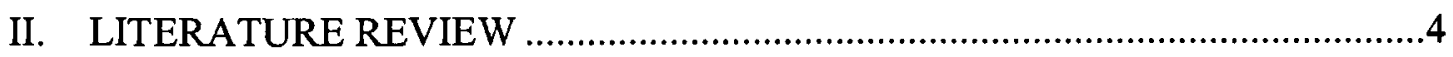

A Brief History of Arts Management ..........................................................

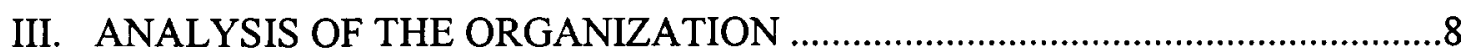

Overview of the Organization..........................................................................10

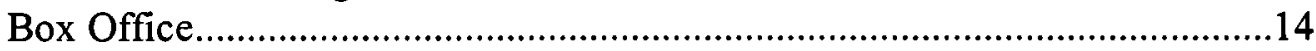

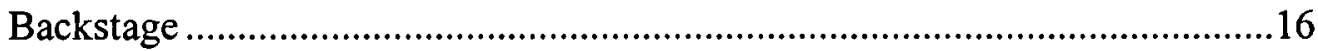

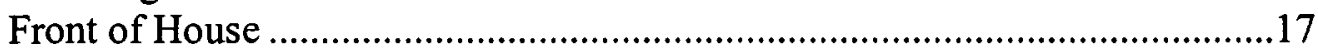

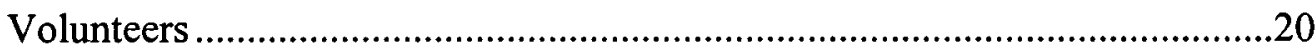

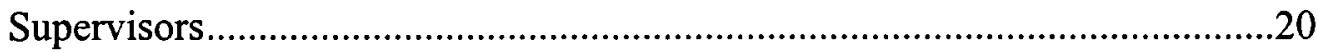

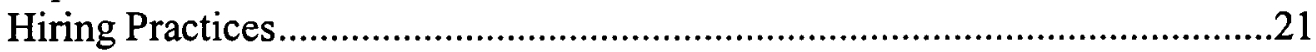

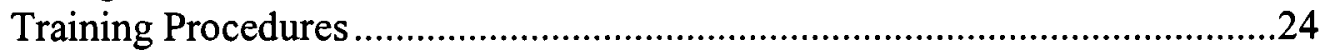

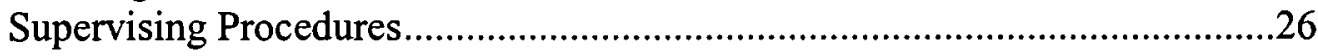

Evaluating Procedures .............................................................................28

Replacement Procedures.........................................................................31

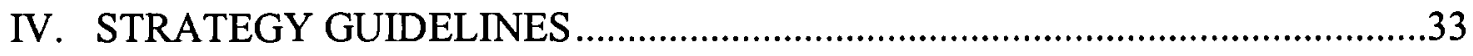

Determining Content of the Strategy ................................................................33

Formatting the Strategy..............................................................................34

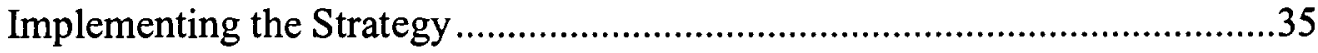

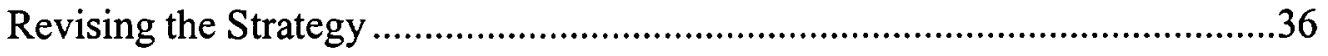

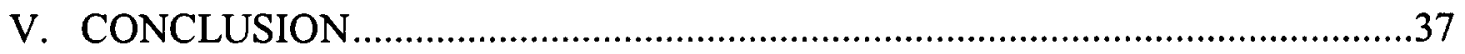

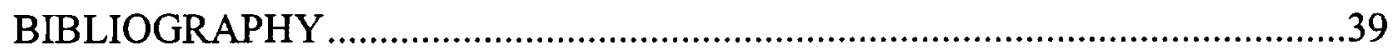

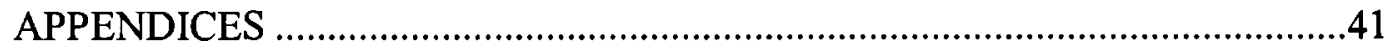




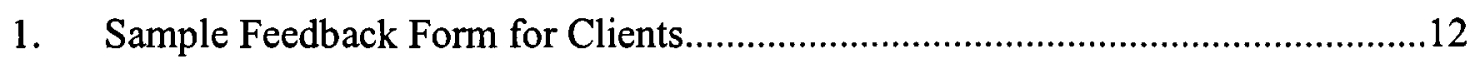

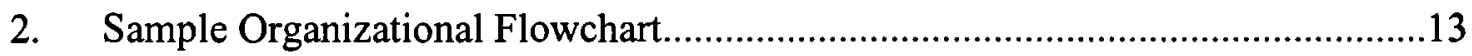

3. Sample Questionnaire for Department Heads...................................................14

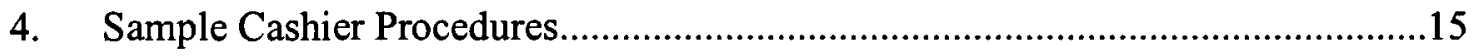

5. Sample Procedures for Sound System …........................................................

6. House Manager Opening Checklist ...................................................................17

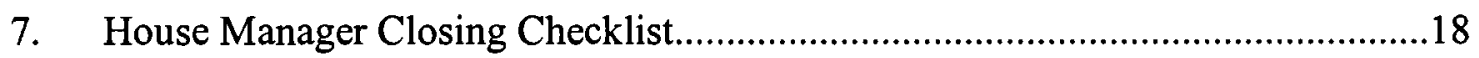

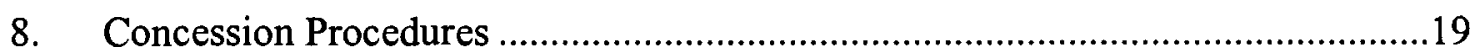

9. Sample Interview Questions for House Managers...........................................23

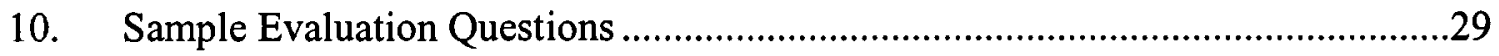




\section{CHAPTER I.}

\section{INTRODUCTION}

Many performing arts venues do not provide written guidelines or employee manuals for their staffs. Events could be run much more efficiently if employees could refer to clear, concise directions in a written form instead of waiting for verbal instructions from a supervisor who is involved with many issues during a live event. However, many managers in the arts field do not know where to begin when trying to develop such instructions.

Managers of performing arts venues lack guidelines to use in developing a production strategy. A prototype will allow managers to create their own written procedures in order for their productions to operate efficiently. In addition, since the staffing of live production has a high turnover rate, the existence of such a plan can assist the management in the hiring, training, and evaluating of production personnel.

Moreover, these tools can create a standard so that productions and clients may be dealt with consistently.

Many venues such as the Jackie Gleason Theatre and Bailey Concert Hall have manuals that state policies relating to clients who use or rent the facility, but very few have a comprehensive manual for employees. There are several reasons why each venue should develop its own strategy. First, it serves as a tool to train employees in their job duties. Second, it familiarizes the employee with the other aspects of production outside their specific area. During an event, it is vital for all personnel to have an understanding of what those in other areas are doing. Third, it provides an objective way to evaluate employees' performance. 
Perhaps one of the more important reasons for developing and implementing a strategy is to include health and safety policies. A venue can avoid lawsuits by ensuring that every member of the staff is issued a handbook and that all are trained properly in fire and safety procedures. As Dr. Randall W.A. Davidson states in an article featured in Theatre Design and Technology:

There are too many individuals who have very little knowledge of the regulations and laws that apply to operating a theatre. What is more horrendous to me is that they do not seem to know they are responsible for knowing, applying and enforcing these mandated laws in their everyday operations.

This proposed strategy is to provide guidelines for the development of a manual for performing arts organizations to use specifically for live events. It is not intended to include personnel policies that would provide the employee with information about benefits, wages, time off, and other related items. It is highly recommended that these are available to employees in written form and there are many sources available to guide managers through this process.

Additionally, this thesis does not address the issues of unions. This is because each union has its own unique set of policies. Every manager who supervises union employees should be very familiar with those policies and should include certain procedures in the completed strategy where applicable. In other words, union policies should always supercede any written procedures implemented within the organization, especially those that refer to health and safety. If an organization has union employees it is imperative that a rough draft be given to the union steward to check for compliance before implementing the final strategy. Regardless of whether an organization deals with 
unions or not, every written strategy needs to be approved by a lawyer before distribution.

If performing arts organizations complete the following guidelines the result will be a customized strategy of written procedures. If implemented accordingly, the strategy will streamline events, provide legal protection, and allow managers to spend less time directing employees. 


\section{CHAPTER II.}

\section{LITERATURE REVIEW}

\section{A Brief History of Arts Management}

The evolution of arts management began in ancient civilizations with the appearance of public forums. Most often these were held for religious purposes and were organized by the religious leaders. These rituals incorporated costumes, scenery, props, music and movement. These services served as a prototype for the state-sponsored stage events that followed beginning in Greece around 534 B.C. The Greeks began a series of play festivals that were managed by the principal magistrate who oversaw the production aspects of the performances. The venues were provided by the cities and the richer citizens funded the festival. The author of the plays served as artistic director.

Similar events were also held in ancient Rome. There were annual events that were sponsored by the state and the magistrates were responsible for auditioning and coordination of the entertainment. As history shows, theatre festivals were scheduled for 100 days a year. This required a high level of management as the managers were responsible for all production aspects of the festivals as well as securing financial support from wealthy sponsors.

After the fall of Rome came the Dark Ages. During this time, there was little state support for organized fundraising and appropriate venues. However, this prompted the performers to begin to organize their own tours in order to continue to make a living. Other than this, there was very little activity in the area of theatre in Europe. At this time, the arts began to flourish in other parts of the world such as Byzantium, India and China. Forms of dance, music, theatre and visual arts became imbedded into these cultures and 
are still present today. As in Europe, the role of the arts manager was very similar as there was still much skill required to organize these events.

By the Middle Ages, the arts in Europe fell under the control of the Christian church. Liturgical dramas were regularly performed and managed by church officials. Soon these dramatic concepts were moved outdoors and performed for the public in forms of festivals and pageants. Non-liturgical dramatic performances were given by mimes and jugglers and thus a new form of public performance was popularized. By the fourteenth century the church has lost control over these productions as they became more and more organized and elaborate. It was during this time that the role of the arts manager became vital to the advancement of the arts. Some productions required up to 300 actors and large sums of money had to be wisely handled. The arts manager was called the "pageant master" and was given a contract and an annual salary to hire actors, coordinate rehearsals and manage every element of the production.

But perhaps the biggest swell in the history of the arts occurred during the Renaissance. This era saw the birth of opera and ballet as well as Elizabethan Theatre and Shakespeare. These forms required the construction of new performance spaces that were designed to incorporate the newest stage technology at that time. As a result, this created the need for stage crew with expertise in rigging, lighting, special effects and wardrobe. This furthered the importance of the arts manager as progressively more and more multifaceted productions required a high level of coordination.

Europe in the seventeenth, eighteenth and nineteenth centuries saw the establishment of many new companies and institutions. In France the theatre, opera and ballet companies were state-run and the performers were salaried with pensions. England 
pass the Education Act of 1870 and the Local Governments Act of 1888 which supported museums and performing arts facilities. The management structure of these organizations was instituted and the function of the arts manager was established.

In the newly formed United States the arts scene consisted of mostly touring troupes that performed in venues with stock sets. The development of the railroad system helped to broaden audiences nationwide still no permanent theatre companies were established. Management responsibilities were handled by the producers and booking agents. This led to a monopoly called The Syndicate that controlled the programming for the country. Eventually the Schubert brothers gained control of this monopoly. Their management structure continues to this day.

Even though permanent theatre and dance companies did not develop during this era, symphony orchestras and opera companies began to take root in large metropolitan cities. Wealthy sponsors founded symphony orchestras in New York City and Boston. The Metropolitan Opera was created in 1883.

In the twentieth century, after World Wars I and II, European and American arts flourished. In post-war Europe the larger arts institutions extended into smaller cities creating a nationwide system of venues and a greater demand for skilled arts managers. This era also saw the arrival of radio and film. This triggered a dramatic decline in audience attendance for live events, especially in the United States during the 1920s. As there were no permanent theatre companies, no loyal audience base could be formed. However the birth of "Off Broadway" theatre renewed interest in the arts. This combined with the baby boom and the expanding educational offerings in the arts increased the need for arts managers to book and run new multi-million dollar arts operations. The 
dance community finally grabbed a foothold in the performing arts arena in the $60 \mathrm{~s}$ and 70s when the Ford Foundation and National Endowment of the Arts (NEA) gave generous support for them that continues to today. Now the arts in the United States are facing a decline in support, especially from state and federal funds. Instead many arts organizations are concentrating their efforts on fundraising from the private sector. 


\section{CHAPTER III.}

\section{ANALYSIS OF THE ORGANIZATION}

The development of a strategy can be of great benefit to an organization by requiring that the entire operation be extensively analyzed. This is an occasion for the management to consider restructuring the framework to attain its highest level of efficiency. The project may even result in an investment in staff or equipment. But it may also expose where there is redundancy or excess. This development phase is an excellent opportunity to increase employee satisfaction and retention, thus gaining support for the organization as a whole.

It is very important for the organization creating the strategy to thoroughly analyze and follow all the steps in order to create an effective manual. A poorly designed manual is one that will be of no use and will most likely be ignored completely by the staff. The goal of the manager should be to create a manual that will be just as helpful to the employee as it is to the organization and the management. As Joseph Lawson puts it:

...it is too easy for verbal explanations given by management and supervisors to be forgotten, misunderstood, or misinterpreted. You need to put in writing all the details, facts, and procedures that concern both employees and their supervisors. Such written or printed personnel policies and procedures reinforce the intent as well as the practical understanding of personnel and benefits policies, standards of performance, safety and health rules, and the like. By publishing and distributing this information in an employee handbook, you can measurably improve the management-employee communication that is the hallmark of a successful business organization. ${ }^{7}$

If the strategy is produced and implemented correctly, the organization may receive many benefits. The first obvious benefit is to the manager. With a properly designed manual the manager makes the task of training new employees easier and 
ensures consistency. Every employee will receive the same the training for their position and will not need to track down the manager to ask for clarification or repetition.

It also gives the manager a tool to refresh current employees on proper procedures. There is an opportunity for the manager to correct "bad habits" and also to implement new procedures. Presenting both new and veteran employees with written procedures holds them accountable for making sure they are in compliance with them.

A high turnover rate in employees is common in producing live events as well as in getting enough staff for an event. This is especially true for the lower-level staff positions that tend to be low salaried with a substantial workload at times. However it is usually these positions that are most needed and keep the organization going. The manual can serve as an excellent tool to cross-train employees. For instance, front of house staff includes house managers, box office staff, ushers and concessionaires. If there is a shortage in one area it is very helpful for a manager to be able to, for example, instruct a house manager to act as a concessionaire. If the procedures for operating the concession stand were written in a detailed and clear manner, it would be possible for the employee to complete the task without needing a supervisor to provide a hurried training session.

Perhaps one of the most important ways a manual can directly benefit a manager is by providing legal protection. Including information about federal and state labor laws, sexual harassment policies, health and safety practices and building codes can prevent legal disputes. In organizations where there is no union, the manual functions as a labor contract. Employees who feel they have everything they need in writing may feel no need to join a union. 
Overview of the Organization

.... [the manager] is responsible for identifying the role, function and procedures for maintaining a policy that encourages employees to work diligently, efficiently, responsibly and ethically in a creative, challenging and supportive environment. This requires knowledge of relevant employee legislation, union agreements, recruitment processes, performance evaluation, training and development schemes, volunteer programs, strategic management and planning. ${ }^{10}$

Before the manager begins to develop a strategy, a meeting should be held with as many employees as possible. This initial meeting should serve two purposes. The first is to make the staff aware that management has decided that developing a strategy would benefit the organization and staff equally. There is no point in creating a manual that will benefit only the organization and management. The current employees will become resentful and probably disregard the manual if they don't see a benefit for them. The idea is not to create a strategy as a means of controlling the staff, but as a means to make everyone's job easier in the long run and have the organization run more efficiently.

The second purpose of meeting with the employees is to have them be involved in the process. It is much more likely that they will follow procedures if it is was they who helped to create them in the first place. Also, who knows best about how to perform a task better than the person who has been doing it for years? This is not to say that old procedures cannot be improved upon, but an employee's perspective about his job should not be disregarded. Tony Alessandra and Michael J. O'Connor base this ideology upon the principle in the book The Platinum Rule:

We think the key to lasting success in business, and the secret to better relationships, is to apply what we call The Platinum Rule: "Do unto others as they'd like done unto them.' 
Employees should be told that their input would be necessary for the creation of this strategy. Ask them to write up their own job description (what they feel their job actually is), and them ask them to write up their procedure or make an audiotape explaining how they perform their basic tasks. Employees should be given ample time to complete this assignment. An interview time should be scheduled with individuals or small groups depending on the size of the organization. During this interview the employee's job description and procedures should be reviewed. Also, a review of any pre-existing written procedures with an opportunity to critique them can benefit

The next step is to conduct interviews. In addition to interviewing the staff, the manager should also solicit feedback from clientele. This information can be extremely useful in determining the weak points of the organization. Strengths of the organization should be identified in order to create written procedures that will maximize these benefits.

Other people to interview are patrons of the venue, artists, and managers of nearby arts organizations. With the exception of patrons, it is recommended that the interview be informal and be treated as a conversation instead of an interview. There will be a greater benefit if a manager can get feedback that is specific instead of a yes or no response. The idea is to determine what areas are in need of improvement and how specifically procedures can be altered to better meet the needs of the organization and clients.

For patrons it is acceptable to distribute formal surveys. Many times a situation arose where a patron became very upset during an event and complained to the management. Check to see if there are any feedback forms that have been archived or any 
other documentation of such an occurrence. These can be very valuable in alerting a manager to areas that need to be addressed. There are several ways surveys can be conducted. If there is a mailing list, the surveys can be sent with the venue's periodic mailings. There may not be a great response using this method. A better method is to have ushers distribute the surveys before a show and to make an announcement before the show. That way patrons have time to complete it during the intermission and turn it in at the end of the show. To encourage a bigger response, it can be made into a drawing where several surveys will be randomly chosen to win free tickets to upcoming concerts. Figure 1 is a guide to be modified for use in any venue in order to gather feedback.

1. What do you like most about our venue? (This is a very open ended question which should prompt the client to talk about a particular strength of the organization.)

2. What would you like changed? (It is better to phrase the question this way instead of a more negative question as "What do you like least?" The former can elicit a more candid response especially if there is very good relationship with the client.

3. Describe your experience with the backstage.

a. Was the staff friendly and helpful?

b. Were there any technical difficulties during your show?

c. Did the event run on time?

d. Did the overall experience meet your expectations?

4. Describe your experience with the box office.

a. Was the staff friendly and helpful?

b. Were there any technical difficulties?

c. Was the box office run in a timely manner?

d. Did the overall experience meet your expectations?

5. Describe your experience with the front of house staff.

a. Were the house managers and usher friendly and helpful?

b. Were there any incidents with patrons that were handled by the house managers?

c. Did the overall experience meet your expectations?

Figure 1 .

Sample Feedback form for Clients (Renters, Presenters, etc.) 
In order to analyze the internal operation of the venue, the manager must begin by dividing the organization into departments. The first step should be to create a diagram of the organizational structure. This should be in the form of a flow chart to indicate the hierarchy of positions. Every person on the staff should be able to find their position on the chart and identify their supervisors. This helps the staff to know their relationship to other departments. See Figure 2.

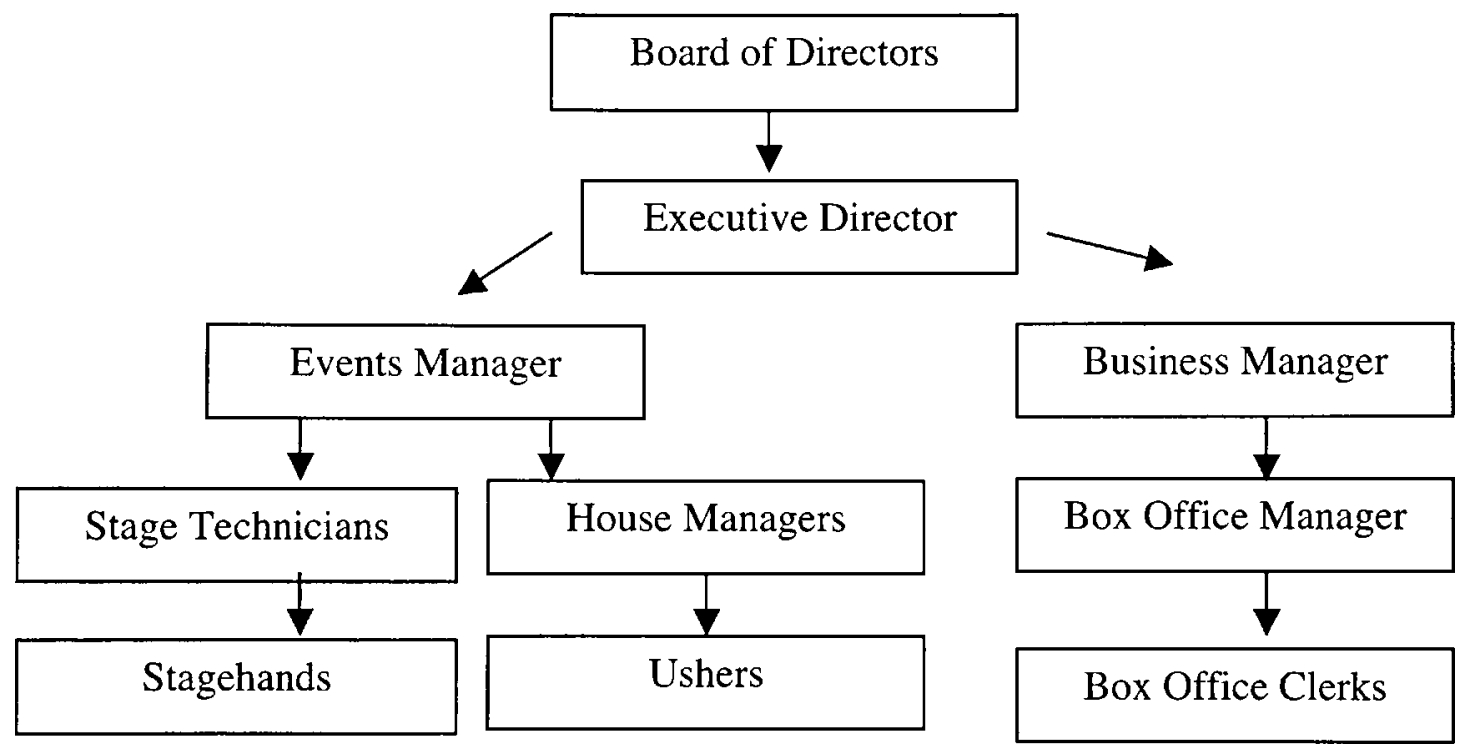

Figure 2.

Sample Organizational Flowchart

If a department has a supervisor, the manager should consult with that person to evaluate working procedures. If there is no supervisor or leader then management should select the most experienced workers from that department to form a committee. The questionnaire in Figure 3 can be used as a starting place for managers to begin this analysis. 
1. Are there any existing written procedures for your department?

a. Is this procedure being followed?

b. Is the procedure meeting our present needs?

c. Do you understand the policy well enough to administer it as it was intended?

d. Are you aware of any misunderstanding about this procedure among your subordinates?

e. Do you think this policy needs to be revised?

f. How and why would you alter this policy?

2. Do you have any suggestions for new policies to be included in a manual?

3. How do you currently train and supervise employees?

4. How would you implement new procedures?

5. How would you ensure these policies are being followed?

6 . How do you currently evaluate employees?

Figure 3.

Sample Questionnaire for Department Heads

The areas that should covered in the procedures manual are those that pertain to safety and legal concerns, start up and shut down procedures, common procedures, troubleshooting procedures and in some instances complicated procedures that would be simplified if it could be referred to in a written form. The idea is not to document every small detail of every task but to choose the most common procedures that would provide the most benefit to the smooth running of the event.

Box Office

Starting with the box office, the first order of business is to examine any preexisting written procedures. A consultation with the box office manager will reveal whether the staff is actually using these procedures. If existing written procedures are 
being followed and the staff agrees that they are the most effective instructions for their tasks, then these may simply be formatted and adapted for inclusion in the manual.

However, it is more likely that even if written procedures exist, they are not being used or need to be updated. The most common situation is that the staff receives verbal training and supervision from the box office manager. If this is the case, the next step is to get in writing what the staff is typically instructed to do from the box office manager (or whomever trains and supervises the staff). The manager, box office supervisor, and staff then need to collectively decide if the current procedures are the most effective ones. If not, alternate procedures should be brainstormed and then implemented for a trial period to see if they are adequate for inclusion in the manual. Figure 4 is an example of procedures for cashiers in a box office written by Luis Roman.

\section{Cashier Duties $^{19}$}

1. At start of day check money in drawer, should always be $\$ 100$.

2. When checks arise write on the check: (unless pre-written on check)

a. Phone number

b. Driver License Number

c. Check Holder must be present!!!

d. Must Do above for E-checks as well

e. Business checks / checks not ran through reader MUST be stamped ${ }^{\star \star \star \star}$ Business Checks DO NOT go through e- Check reader

3. At the end of your shift balance your drawer.Get total income and breakdown from computer.

a. Click Reports > by Day > Clerks > Reports for 1 clerk

\section{Figure 4.}

Sample Cashier Procedures 
Backstage

The next area that could be looked at is backstage. Management must look at the areas that could benefit from written procedures. For instance, in the area of sound reinforcement and lighting there may be a benefit in having instructions printed about setting up a common set up, such as one person speaking from a podium. By consulting with the audio engineer and lighting director, it can be determined how the board can be set in a default mode after a show so that a novice could operate it for such an event. Standard procedures such as starting up and shutting down equipment should be included in the manual as well as any other information related to safety. Figure 5 is an example of such procedures written by Donald Endriss.

Starting up the sound system may seem very intimidating at first, but if you follow the instructions and remember to breathe deeply before attempting each step, you will not be stressed. Stressing yourself out is unnecessary, it's not a nuclear reactor, and you'll be fine. Here's the order to get the sound system up and running.

(Read instructions first, and then do)

1. Go up to the sound booth, and turn on the light. Find the circuit breaker box in the far corner and turn on breaker number 12 . This turns on the soundboard and all the equipment in the rack. It takes about 20 seconds for everything to fully turn on.

2. Now you want to turn on the amps. Let's start with the center cluster. Between the door and the rack, there is a metal box marked "C A" (looks like an electrical outlet box). You have to press the red button in; this tells the center cluster of speakers to start powering up the amps, it does everything automatically. One LED bulb lights up followed by the other. When both of the LED lights (red and green) have lit up, then you have successfully turned on the center cluster amplifiers. The process takes about 30 seconds, have patience. If nothing happens try pressing the button again.

Figure 5.

Sample Procedures for Sound System ${ }^{20}$ 
Front of House

Another department that will need to be examined is the front of house.

Procedures should be created for opening and closing the building, emergency evacuations, medical emergencies, running concessions, and accommodating the disabled. Unlike the backstage, front of house employees do not have many technical procedures that need to be documented but since they are involved with the pubic much attention needs to be given to legal and safety issues such as fire and building codes, American with Disabilities Act, and health and safety laws. Figures 6-8 are examples of front of house procedures that have been presented in a checklist format.

\section{HOUSE MANAGER OPENING CHECKLIST}

Performance:

Date:

Initials

1 Call Security $(X X X-X X X X)$ if necessary to unlock building doors and stage door

2 Check to make sure loading dock is clear of cars, put out cones if necessary

3 Check state of area outside lobby doors, pick up newspapers, trash, etc.

$4 \quad$ If dark, be sure that outside globe lights are on

5 Check parking lot barricades

\begin{tabular}{r|l|l}
6 & Unlock/lock necessary lobby doors \\
7 & & Distribute radios FOH \\
8 & & Unlock concession stand, get cash box \\
9 & & Print out volunteer sign-in sheet \\
10 & Set up any necessary tables and chairs, make/post any necessary signs \\
11 & & Turn on hall lights, check trash and bathrooms in back hallway \\
12 & & Close office hallway door, prop open opposite door
\end{tabular}

\begin{tabular}{l|l|l}
13 & Unlock/check wardrobe room \\
14 & Unlock/check dressing room 1 \\
15 & Unlock/check dressing room 2 \\
16 & Shut electric room door, check pit door, check makeup room \\
17 & Unlock/check dressing room 3 \\
18 & Unlock/check dressing room 4 \\
19 & Unlock/check dressing room 5
\end{tabular}

Figure 6. 


\section{HOUSE MANAGER CLOSING CHECKLIST}

Performance:

Date:

\section{Initials HM1}

Sweep mezzanine

Return usher chairs to position

Remove any stray objects, tables, signs etc.

Lock down mezzanine even, check bathrooms, turn off lights

Collect doorstops and programs

Lock down mezzanine odd, turn off lights, including chandelier and patio lights

Lock/check women's Orch Odd

Move mezzanine sign to steps, check couch arrangement

LockTurn off lights orch odd

Sweep Orchestra

Lock/Turn off lights Orch Even

Lock/check bathrooms Orch Odd, check water fountains

Move mezzanine sign back to steps

Check couch arrangement

Clean up/arrange/lock $209^{*}$

Clean up/arrange/lock Curren Room*

Clean up/arrange/lock Maestro Room

Check bathrooms, turn off lights

Turn off hall lights, lock stairway doors

Check under stairway, check fire door

Lock stairway door

Go out glass doors, (don't get locked out!), tidy lobby area

Check fire doors

Lock/check dressing room 5

Lock/check dressing room 4

Lock/check dressing room 3

Shut electric room door, check pit door, check makeup room

Lock/check dressing room $2^{\star *}$

Lock/check dressing room $1^{\text {** }}$

Lock/check wardrobe room

Turn off hall lights

Unprop hall door

Check that all doors in hall are locked and shut

Check outside stage door, remove signs and cones if necessary

Turn off lights in hallway, shut double doors

Tidy chairs in hall, check bathrooms

Lock Scene Shop stairwell

Check barricades

Figure 7. 


\section{Concession Procedures}

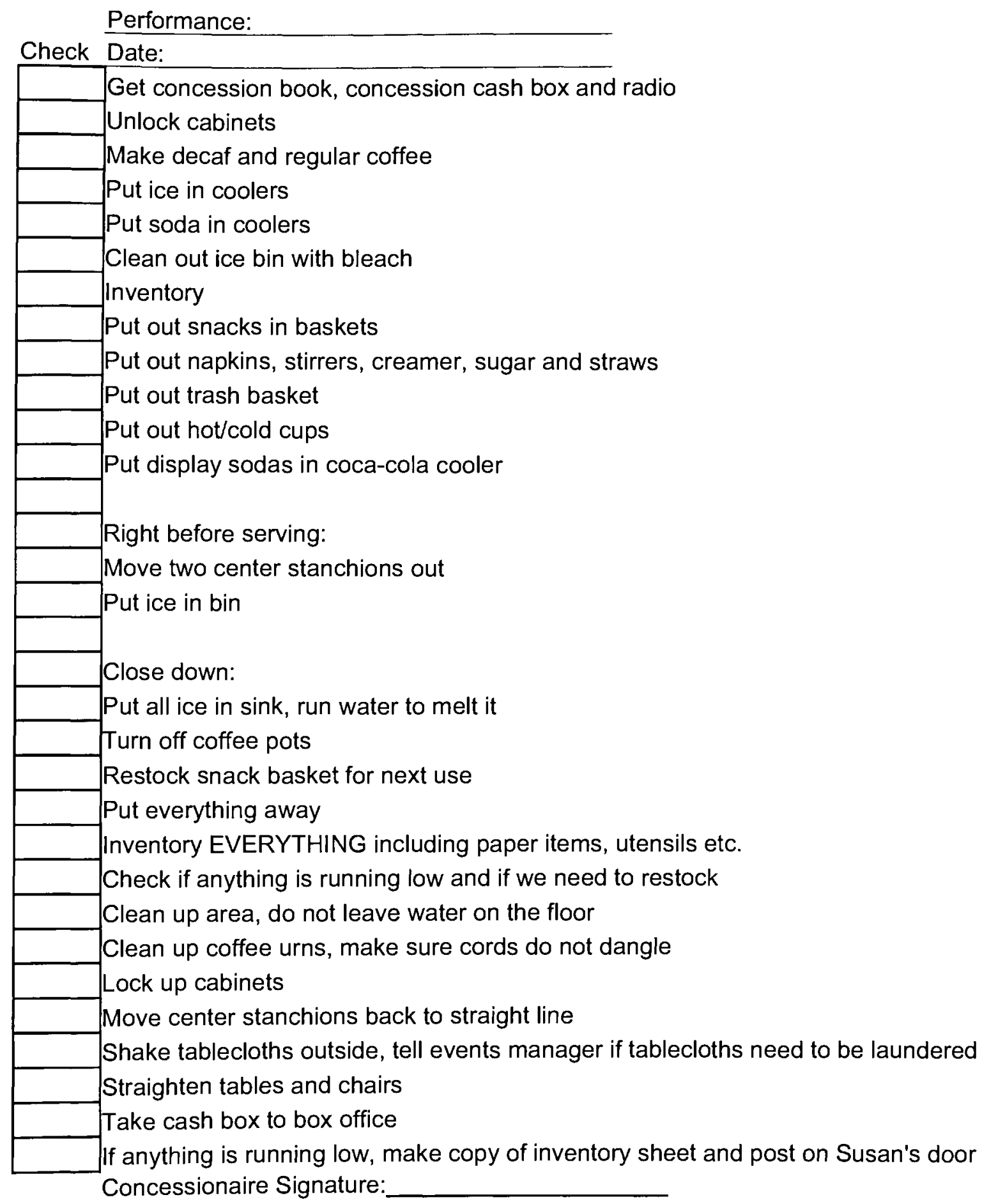

Figure 8. 
Volunteers

Many performing arts organizations use the services of volunteer ushers. Because they are not paid employees they should be handled differently. However, front of house procedures still need to be enforced for them as the organization is legally responsible for them as they would be for other staff members. It is recommended that orientations be given for new volunteers and periodic "refresher" sessions be held for current volunteers. These sessions can coincide with an annual thank-you gathering where the relevant policies can be reviewed.

\section{Supervisors}

Middle and upper level management should be analyzed as well. While not usually required to carry out specific procedures, managers oversee several departments simultaneously during a live event. This can involve a lot of distraction and having a checklist can keep the manager on course. Therefore interviews and research in this area should be performed as well to determine the most critical or often overlooked items to include in the strategy.

Of course, upper level management is not only concerned with supervising procedures during event. More importantly, they are responsible for the entire staffing of the organization from hiring to firing. This is where the analysis of the organization is most crucial because without proper personnel management beginning with the hiring process, the organization cannot operate efficiently. This following quote stresses this important factor: 
Staff are the human resources required to fulfill the mission and support the strategic plan. Staffing is the key element in the success or failure of the enterprise. For example, the Queensland Performing Arts Trust's corporate objective for employees provides a focus for work practice, the culture of the organization and for human resource management policy and procedure in that arts center. A strategic plan for recruiting, training, performance and practices has been designed to carry out the work of the Trust in accordance with the corporate objective. $^{7}$

The following sections emphasize the importance of management responsibilities in hiring, training, supervising, evaluating and replacing personnel. They will also explain how to develop procedures and implement them in these fundamental stages. The result of these processes will then determine what will be included in the strategy.

\section{Hiring Practices}

To build an effective organization, it should begin with hiring the right people. While it should not be actually included in the manual that will be distributed to employees, it should be treated as procedure that should be written out and used consistently. This is also a reason why creating an accurate job description is so important. It not only sets the standard for current employees it also helps to find the best candidate for that position should it become vacant.

The job description is described by the following quote:

The purpose of a job or position description is to provide accurate and objective information about the duties and requirements of the position. It outlines the tasks, duties, and responsibilities of the position: the relationship of the position to other positions in the organization; the relationship to the corporate objectives and mission of the organization; and the personal qualities in relation to the qualifications, knowledge, skills, abilities and competencies required to do the work. $^{?}$ 
This job description should be used to develop interview questions. Another reference to look at is the previous employee's evaluation. This is a valuable tool for avoiding traits you do not want, and finding traits that the previous employee perhaps lacked. Another very important basis for having written hiring procedures is to make sure the interviewer does not unintentionally break the law. It is illegal to question a candidate about age, marital status, family, national origin, disabilities or religion. However, by having questions carefully worded ahead of time can assess whether the candidate can meet your needs in terms of work schedules, ability to write and communicate clearly and effectively, and ability to perform specific tasks.

It is very to important to keep in mind that the way a question is phrased should be appropriate for the type of person that is been interviewed. For instance, if a technical person is being interviewed and the level of technical skills is the most important aspect of the job then the questions should focus on determining that. The questions should be non-objective and be able to be answered with yes, no or another succinct response.

However, if someone is being hired for a position that involves a lot of interaction with the public then objective questions should be asked to test their communication skills. Ask open questions, not ones that can be answered with yes or no. Begin questions with "describe" or "explain." If there are situations that arise frequently that require an employee to have a quick response than describe than scenario and then ask the person to describe how he or she would handle the situation. Figure 9 is an example of interview questions for a house manager position. 
1. Do you have any background in theatre?

2. Do you have any background in customer service?

3. Do you have any type of management experience?

4. What are four adjectives to describe you?

5. How would you respond to a patron who is irate because they have duplicate tickets for seats that are taken?

6. In general, what is your availability?

7. Describe a situation where you had to make a quick decision on your own?

8. Describe your ability to recognize when action needs to be taken without be directed to do so.

9. Are you perceptive, do you pay attention to details?

10. Are you able to communicate effectively in a polite manner?

11. Would you be comfortable with supervising and directing a large amount of people?

12. Are you able to be authoritative and firm when necessary?

Figure 9.

Sample Interview questions for House Manager:

During the hiring process the manager should focus on presenting the candidates with a thorough and accurate description of the job and to find the candidate who best understands the goals and objectives of the organization. The most common situation is having several candidates with varying levels of abilities in different areas and then needing to make a final decision. A candidate who may appear to have less abilities but a better understanding of the organization will end up being the better employee if he or she receives the proper coaching from the manager. This is where the strategy becomes most useful. Too often, new employees become disgruntled when they feel they were misled about what their position entailed. Clear communication is set from the beginning, including the specific procedures required to complete tasks. This eliminates any confusion or misunderstanding between the employee and manager's expectations about the job. 
The hiring process often becomes a great burden to performing arts organizations because of the time and money spent in the recruitment process. Valuable time can be saved and errors avoided by having these hiring procedures set in advance. The interviewer needs to document the interviewer, preferably by videotaping, but alternately by making an audio recording. Simply relying on memory or jotting down notes is not comprehensive and would not be accepted should the candidate suggest there was any prejudice or indiscretion. Legal issues are of great concern and having documentation of the entire hiring process can rescue an organization from entering legal dispute. When making a final decision in the selection process, the organization runs the risk of the rejected finalists filing a lawsuit. The organization must be prepared to provide documentation to justify the decision.

Training Procedures

After hiring a new employee, management must decide how to train them. This quote by William Byrnes describes the challenges to arts managers:

Due to their limited resources, arts organizations have no training programs. Training usually takes place only after costly errors have been made by a new employee. ${ }^{2}$

Every new employee should be given an orientation to get an overview of the organization, staff and job duties. An orientation can begin with a tour of venue followed by a short staff meeting to make introductions to the staff. A new employee should be given the time to start off on the right foot with his or her co-workers and holding an informal meeting where everyone can introduce themselves and explain their role in the organization. 
There are several forms of training: on the job, cross training, coaching, apprenticeships, and modeling. On the job training is when an employee is given a demonstration and is then expected to begin performing the task. It is essentially calling for the new employee to learn as they go along on his or her own, with little formal training. This type of training can definitely benefit from a manual because management can expect that the employee will refer to the manual as needed when they are uncertain of a new procedure.

Cross training is a form of training that is especially useful for smaller performing arts organization in particular. In this method, the new employee may be specialized in one area but is still expected to be able to perform other job functions as needed. There may be many times when an employee is needed to fill in for another position. It can be harmful to an organization not cross-train their employees. Having only person who can perform a necessary can be risky if that person was ill or left unexpectedly. Cross training is usually accomplished by job rotation and modeling where the new employee is cycled through each department. Modeling involves the employee observing a co-worker or superior performing a task and modeling their procedures.

Coaching is having a superior observe the new employee and giving very specific feedback about their skills. This is often continued until the supervisor is confident that the employee is able to perform the task on his or her own. While an ideal way to train employees, it is often impractical or impossible for a supervisor in performing arts organization to devote enough time to this type of training.

Apprenticeships are the form of training most often used in the arts. This is involves the novice working very closely with an expert co-worker in the same position. 
The apprentice is not given any individual responsibilities until they have developed the required amount of proficiency.

For most arts organizations, a blending of the cross-training and apprenticeship methods of trainings combined with a procedure manual reference is the most effective way to train new employees. If the responsibility of guiding a new employee is delegated to someone other than the manager then the manual serves as a way for management to convey its expectations.

\section{Supervising Procedures}

Once an employee has been hired and initially trained, it is important for management to continue to enforce the procedures in the handbook. It is easier to engage in periodic coaching sessions with a new employee than it is to "unteach" bad habits that can develop when there is no formal supervision. For arts organizations in particular, it is unrealistic and, in most cases, unnecessary to expect the manager to be constantly supervising employees. However, especially with the implementation of a procedure manual, it can make the task of supervising many employees at once much more feasible. If the strategy has been correctly researched, developed, and implemented then employees know they will be held directly accountable for either following or not following the procedures outlined in the manual. If the guidelines have been followed, then the employees have been involved in the entire process so there should be very little resistance when the manual is implemented.

So the only supervision from the management at this point is to periodically observe that procedures are being followed. (Note: These supervising guidelines are only 
intended to pertain to ensuring that procedures are being carried out correctly. There are many other aspects of employee supervision that have been intentionally omitted, as they do not apply to the scope of this text.) If the manager finds that some employees are not complying with the manual than the first step is to determine the reason why. There are several possibilities to consider; either the employee is unaware he or she is not following procedures, or he or she is aware and chooses not to comply. If it appears that employee is unaware that they are not following procedures either because they did not fully understand the procedures or because they had forgotten, then the manager must ascertain if the employee received adequate training. Does the employee require additional training? Every individual has their own learning style so if on the job training was initially used to train the employee a different form such as coaching should be used to reinforce the right procedures. If it doesn't seem that lack of training was the reason, and the employee consciously chooses not to follow procedures than disciplinary actions should be taken. Before reprimanding an employee, he or she should be given an opportunity to explain their actions. It may be that they have a different way of completing task that could be more efficient. If this is the case the employee should be reminded that he or she should share this idea with management before disregarding the manual. In fact, it is necessary for the manual to be periodically updated at the suggestions of the staff, but that does not grant authorization to ignore policies.

However, if it is determined that an employee intentionally does not follow procedures without basis, then it should be noted in that employee's evaluation and that employee should be supervised closely for a period to make sure they are following 
procedures. If this is not possible for the manager then the employee should be required to turn in daily reports or checklists for a period of time.

Usually, all that is required of the manager is to make periodic, unannounced observations to demonstrate to the staff that the manager is resolute in ensuring that the manual is being adhered to. If the staff perceives that the manager doesn't care then they won't either. The manager must document their observations whether positive or negative. The language and tone in the notations should be the same for every employee and should refer only to job performance instead of subjective criteria. These inspections and documentations are also very important for the evaluation process discussed in the next section.

\section{Evaluating Procedures}

It is recommended that an informal evaluation be held at least once a year, and more often if there are any disciplinary problems. There are several reasons why management should hold evaluations. First it gives the employee feedback about their performance. It is just as important to tell a valuable employee how much they are appreciated, as it is to correct the behavior of a problematic employee. Evaluations are also a great time to gain feedback from the staff about the overall effectiveness of the organization. It can also make the employees feel less defensive if they feel it is also an opportunity for them to evaluate the administration. The goal of the evaluation is build morale for the employees that deserve it, correct the mistakes of negligent employees, determine if an employee should be dismissed, and inspire apathetic employees. 
The approach of evaluations within a performing arts organization is an individual choice. For some, a very formalized system is not appropriate and will not be taken seriously by the staff. It is very important for the manager to decide which method will be most effective for the staff. It is not recommended that evaluations be skipped altogether.

The formal method would involve an annual meeting to be scheduled in advance. A self-evaluation form and a direct supervisor form should be given. Figure 10 is a template that can be used as a guide for creating an evaluation form, The employee should be given a couple weeks to fill these out. The manager should fill out the same evaluation form for the employee prior to the meeting as well. During the evaluation, the manager should go over each item with the employee and together the employee and manager should decide on the final comments. If an agreement cannot be reached then the employee should sign the line on the evaluation that stipulates that the employee has reviewed the comments and disagrees with them. The combined evaluation should be placed in the employee's file.

1. Quality of Work: Measures employee's ability to efficiently and correctly complete assigned tasks and proper procedures. (circle rating)
a. Exceeds
b. Achieves
c. Below Standard

2. Dependability: Measures employee's attendance and tardiness record. Refers to employee's ability to work independently and commitment to organization. 

a. Exceeds
b. Achieves
c. Below Standard

3. Initiative: Measures employee's ability to recognize what tasks need to be completed and when without the need for direct supervision. Ability of employee to respond quickly and effectively when action is required.
a. Exceeds
b. Achieves
c. Below Standard

4. Organizational Awareness: Evaluates the employee's understanding of his or her relationship to the hierarchy of the organization. Evaluates employee's familiarity and adherence to policies and procedures.
a. Exceeds
b. Achieves
c. Below Standard

Figure 10.

Sample Evaluation Questions

The formal method may not be appropriate for some smaller, less corporate organizations. In these situations, it is better to conduct evaluations in a more conversational tone. It is still important to schedule a meeting with the employee in advance in case he or she wants to prepare some topics they would like to discuss. In this scenario the employer should still prepare written comments to discuss based on the observations that were noted during the supervising process. Careful notes should be taken or an audiotape made (with employee consent) during the evaluation and everything put in the employee's file. 
After reviewing the evaluation, management should decide what action, if any, should be taken. Should the employee be terminated or demoted? Should goals be set? Should a promotion or raise be given? Should more or less responsibilities be assigned? Is additional training needed?

Evaluations when performed prudently are a very valuable tool. The inclusion of a procedure for evaluations in the manual is also a choice for the management. If it is decided that there is one form that can be used for most of the staff then that can be included. However, it is very important that a procedure for conducting evaluations is developed even if it is just for the manager. This is to ensure that the organization has documentation should any legal issue arise due to an employee grievance regarding termination or otherwise.

Replacement Procedures

After following the supervising and evaluating guidelines, management may decide that an employee should be considered for dismissal. Following set procedures can be helpful for many reasons in this area. Termination of an employee should be considered only when every prior procedure has been followed and still the employee's performance is unacceptable. If a legal dispute were to arise, this demonstrates that the employer has documentation of the hiring, training, supervising, and evaluating processes.

If after the first evaluation the employee is determined to be inadequate then he or she should be placed on probation. During this time expectations should be clearly stated or goals should be assigned and a deadline set. These should be given in written form and 
the employee should sign that they received it. The manager must be present as often as necessary to observe if the employee is making progress or not and document this. If after the probationary period the performance is still not satisfactory then the manager to provide coaching and feedback should give a final effort. If it is finally determined to end the employment then it should be made clear to the employee that all procedures have been followed and that enough documentation exists to justify the termination. 


\section{CHAPTER IV.}

\section{STRATEGY GUIDELINES}

Determining Content of the Strategy

After the manager has fully analyzed the organization, including every department and every human resource procedure (hiring, training, supervising, evaluating and replacing), then it should be fairly straightforward to determine the content of the manual.

Once management has interviewed and agreed with staff on some preliminary written procedures then a few months should be allowed to assess their importance and effectiveness. Another meeting should be held after this trial period to collectively decide on which procedures should be included. There should also be an opportunity at this time for the first draft to be revised if corrections are needed. As stated earlier, the content should include safety and legal concerns, start up and shut down procedures, common procedures, troubleshooting procedures and complicated procedures needing clarification.

The matter of how the strategy should be designed depends on the size and scope of the content. For smaller organizations it may be more suitable to design the manual in a less formal or overtly corporate format. Tone can be conversational and approach may be laid back and humorous where appropriate as demonstrated in Figure 4. This is also a good way to implement the manual so that employees view it as a guide they can refer to help them.

However, for larger more commercial venues it may be more appropriate to have step-by-step guidelines presently as clearly as possible. In either case, language should be 
easy to understand with specific terms defined. Instructions with visual diagrams are most useful for computer-based procedures or for procedures involving technical equipment. Figure 3 is an example of such instructions. A great way to test the clarity is to, for example, ask a house manager if they are able to follow the procedures for starting up the light board. While he or she is not expected to perform this task this exercise may provide suggestions about how to better put it into words.

Checklists are probably the most helpful written item for newer staff or part-time staff that need more reiteration. Checklists can be followed without direct supervision and can ensure that the task be performed accurately and completely. Consider making many copies of checklists and having the staff date and sign a copy each time they complete the tasks. This automatically makes employees accountable for their work and reduces excuses. Figure 8 is an example of checklist that requires the employee to check off each task as it is completed and sign off on the bottom of the form.

Also an excellent use of a checklist is to divide tasks among several employees. For example, one person can complete tasks 1-10, and the other can complete 11-20. This can save an organization much time and money. Checklists can allow a supervisor to attend to other tasks.

Formatting the Strategy

Once the content has been finalized then the next step is to decide on how the procedures should be formatted. The most familiar way is in the style of a handbook. Another option is to have it electronically available on a website or to email as a .PDF file to the staff. This is a very easy and inexpensive method that should be done but only 
as a supplement to a hard copy of a handbook. Many positions in venues that produce live events do not involve computers. The procedures need to be readily accessible to all employees. Given the nature of live events, it is also very important that the handbook be of sturdy construction and user friendly. The best option is to have it hole punched so it is very easy to flip to any page and stay open while performing the task described. This also makes it cost-effective when revising the manual. If mistakes are found or improvements and additions are needed, then it is easy to remove the flawed pages and replace with the new pages. That way an entire handbook does not need to be reproduced and revisions are quick and easy. The cover (front and back) should be made of a durable and waterresistant material. The pages should also be laminated, as this will extend the duration.

If staff is expected to abide by the strategy then the manager needs to demonstrate that maximum effort and intent went into the entire creation of the end product. The more professional and polished it looks will motivate the staff to view it as a significant tool to be implemented in the organization.

Implementing the Strategy

The implementation process should begin by the manager meeting with the heads of each department. It needs to be stressed that the strategy needs full cooperation from all supervisors in order for it to be effective. The handbook should be distributed to the supervisors to pass on to their direct reports and all procedures should be reviewed. The supervisors should be told that they need to reserve time to discuss the procedures with their subordinates and that they need to report when it has been completed. They must 
inform everyone that they will be expected to follow this protocol and if not found in compliance, disciplinary steps will be taken.

Revising the Strategy

After the implementation process, it is inevitable that revisions will be necessary. The most effective manual is one that is frequently updated to reflect the evolving needs of the organization. Employees will disregard a manual that is out of date with obsolete procedures still included. Approximately six months after the strategy has been implemented, a meeting should be held to evaluate it. Suggestions should be noted at this time about employees' observations of its effectiveness. Procedures may be to be revised, created, or eliminated.

If formatted as previously suggested, then revising the manual will be very simple. The superceded pages can be removed and easily replaced with the new pages. Since many handbooks have already been distributed it is advised that labels with the date of revision to be placed on the cover so employees will not accidentally refer to an old handbook that is missing the updated pages. If any electronic copies or web pages have been designed, they will need to be updated as well. Fortunately, this will be a very simple and inexpensive revision. 


\section{CHAPTER V. \\ CONCLUSION}

Based on the research performed, it is concluded that performing arts organizations will greatly benefit from the development and implementation of a production strategy. Since many arts managers lack basic management skills, the guidelines provided in this thesis will help to create a tool in the form of a manual. The thesis will lead arts managers through the stages of analysis and research, development, implementation, and revision. It was found that most corporate management techniques were not relevant to arts venues. However, by combining general management techniques with research in the performing arts, guidelines for a production strategy was developed to assist arts managers.

The scope of this thesis covered the production of live events only. However, during the research process it was discovered that in order for events to run as smoothly as possible the organization must also look at general personnel management as well. The concept is to start at the roots of human resources, from the hiring process through training, supervising, evaluating and replacing processes. It was found that this lays the foundation for a production strategy to be implemented and will greatly improve the degree of effectiveness.

Another conclusion was made that if used during the training process, the strategy will improve employee performance. It will provide correct procedures in written form and by will hold the employee accountable for their actions (or lack thereof). Also if all employees are reliably trained in this same manner then that will ensure that events run 
smoothly and that clients are treated in a consistent manner. This would then result in improved client and patron satisfaction.

Another huge advantage for the organization as a whole is that once the strategy has been put into action it will free up arts managers' time. It will allow them to devote less time to in person management of the staff and give them an opportunity to focus on other tasks such as programming and fundraising. 


\section{BIBLIOGRAPHY}

BOOKS:

1. Alessandra, Tony and O'Connor Michael J. The Platinum Rule: Discover the Four Basic Business Personalities-and How They Can Lead You to Success. New York: Warner Books, Inc., 1996.

2. Byrnes, William J. Management and the Arts. Burlington, MA: Elsevier Science, 2003.

3. Campbell, Nancy J. Writing Effective Policies and Procedures: A Step-by-Step Resource for Clear Communication. New York: Amacom, 1998.

4. Chong, Derrick. Arts Management. London: Routledge, 2002.

5. Diamond, Susan Z. Preparing Administrative Manuals. New York: Amacom, 1981.

6. Fitzgibbon, Marian. Managing Innovation in the Arts: Making Art Work. Westport, CT: Quorum Books, 2001.

7. Lawson, Joseph W. R. How to Develop an Employee Handbook. New York: Amacom, 1998.

8. Nelson, Bob. The Management Bible. Hoboken, NJ: John Wiley and Sons, Inc., 2005 .

9. Page, Stephen B. Establishing a System of Policies and Procedures. Westerville, OH: Process Improvement Publishing, 1998.

10. Radbourne, Jennifer and Margaret Fraser. Arts Management: A Practical Guide. St. Leonards, AU: Allen and Unwin Pty. Ltd, 1996.

11. Reiss, Alvin H. The Arts Management Reader. New York: Marcel Dekker, Inc., 1979.

12. Schneider, Richard E. and Mary Jo Ford. The Theatre Management Handbook. Cincinnati: Betterway Books, 1999.

13. Walsh, John F. The Indispensable Staff Manager: a Guide to Accountable, Effective Staff Leadership. Westport, CT: Praeger Publishers, 2003.

14. Webb, Duncan M. Running Theatres: Best Practices for Leaders and Managers. New York: Allworth Press, 2004. 
15. Ackler, Bryan H. and Stephens, Lila L. "You Want Me to Do What?: The Fair Labor Standards Act as It Applies to Entertainment Industry Workplaces." Theatre Design and Technology 39 no. 1 (Winter 2003), http://gateway.proquest.com/openurl?ctx ver=Z39. 88-2003 \&res dat=xri:pqil:res ver $=0.1 \& \mathrm{rft}$ val $\mathrm{fmt}=$ ori:format:pl:ebnf:fulltext\&res id=xri:iimp\&rft id=xri:iipaft:aarticle:fulltext:00308330.

16. Basile, Frank. "Developing a management procedures manual." Journal of Property Management 51, no. 6 (Nov-Dec 2006), http://find.galegroup.com/itx/infomark. do?\&contentSet=IACDocuments \& type $=$ retrieve \&tabID=T002\&prodId=EAIM\&docId $=\mathrm{A} 4608558 \&$ source $=$ gale $\&$ userGroupName $=$ flstuniv $\&$ version $=1.0$.

17. Cohen, Claire. "Striving for seamlessness: procedures manuals as a tool for organizational control (The Rhetoric and Culture of HRM)." Personnel Review 24 no.4 (June 1995), http://find.galegroup.com/itx/infomark.do?\&contentSet=INGENTA\&type =retrieve \&tabID=T002\&prodId=EAIM\&docId=CA89798534\&source=gale\&user GroupName=flstuniv\&version $=1.0$.

18. Davidson, Randall W.A. "The State of Health and Safety in the Theatre: 2001." Theatre Design and Technology 37 no. 3 (Summer 2001), http://gateway.proquest.com/openurl?ctx ver=Z39.882003\&res dat=xri:pqil:res ver $=0.1 \& \mathrm{rtt}$ val $\mathrm{fmt}=$ ori: format:pl:ebnf:fulltext\&res id=xri:iimp\&rft id=xri:iipaft:aarticle:fulltext:001703 $\underline{58 .}$

\section{INTERVIEW SOURCES:}

19. Luis Roman, Box Office Manager, Bailey Concert Hall. November 21, 2006

20. Donald Endriss, Audio Engineer, Bailey Concert Hall. January 15, 2007. 


\section{APPENDIX A.}

Sample Procedures for Cashier Duties ${ }^{19}$

1. At start of day check money in drawer, should always be $\$ 100$.

2. When checks arise write on the check: (unless pre-written on check)

a. Phone number

b. Driver License Number

c. Check Holder must be present!!!

d. Must Do above for E-checks as well

e. Business checks / checks not ran through reader MUST be stamped

**** Business Checks DO NOT go through e- Check reader

3. At the end of your shift balance your drawer. Get total income and breakdown from computer.

a. Click Reports > by Day > Clerks > Reports for 1 clerk

\begin{tabular}{|l|l|} 
\\
b. On the Report for 1
\end{tabular}

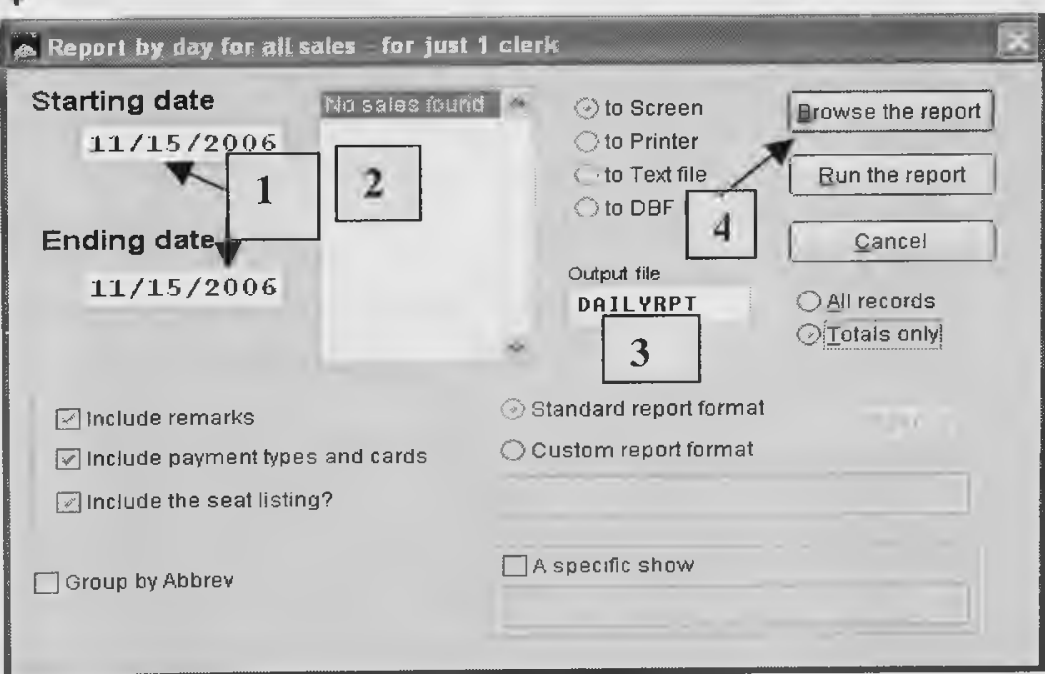


g. Ensure that your cash balances.

$\boldsymbol{E x}$. Count out your cash income, our remaining money should equal $\$ 100$.

Ex. Count out your $\$ 100$ bank,

Your remaining cash should equal your cash income.

h. Balance your credit card total.

a. DRAWER MUST NEVER BE UNDER \$100!!!!

4. Fill out Session Report using the above report.

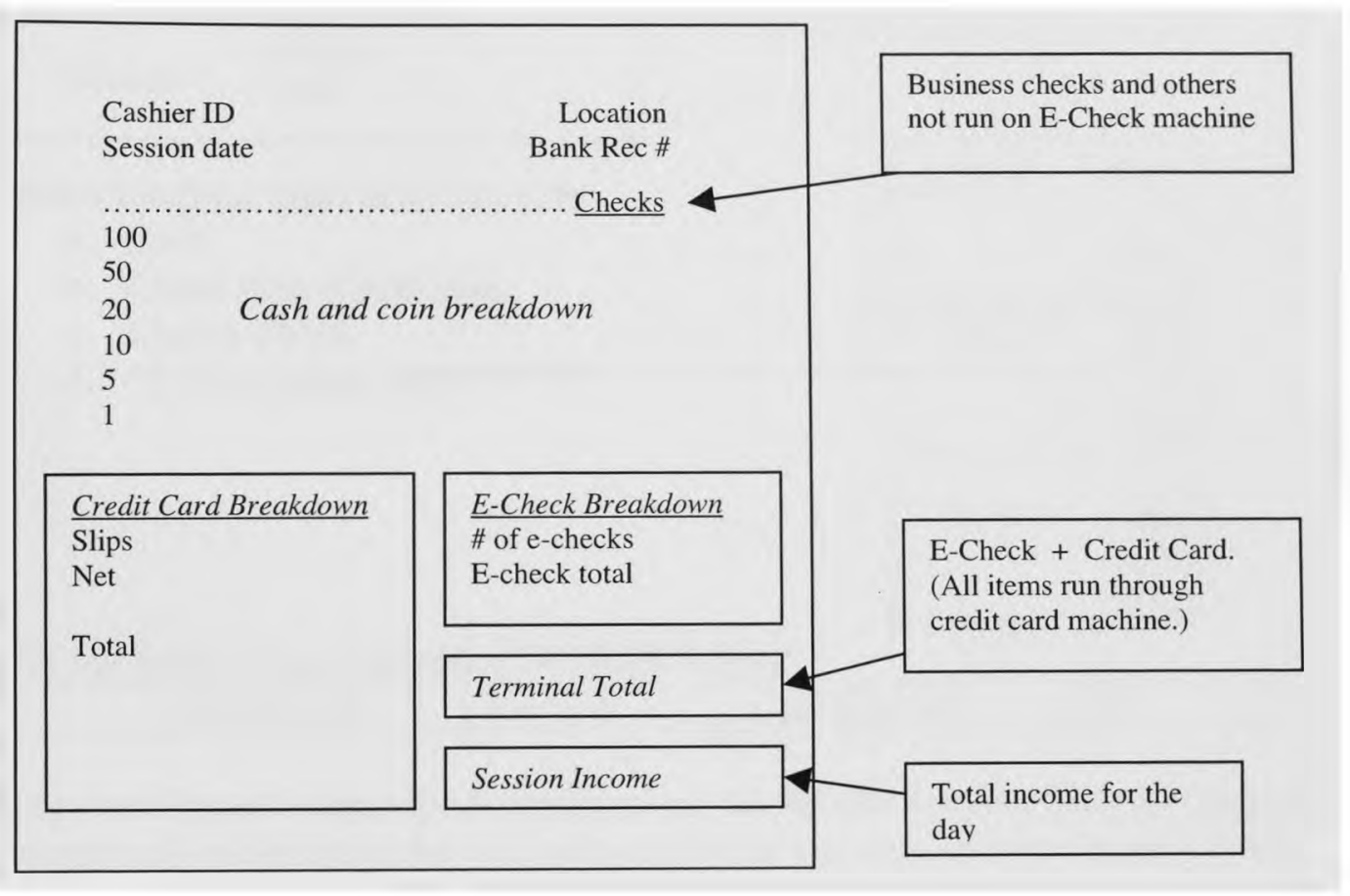

5. Fill out Bank Deposit Slip with cash, coin and checks (non e-check) as needed. Also put your operator number and the bank rec number on this slip.
a. Cash
b. Coin
c. Cash Total
d. Check (non E-check)
a) Check number
b) Check amount

6. Sign and fill out session cash deposit form.
a. Cash / Check (non E-check)
b. Total 
7. Make envelopes.

\begin{tabular}{|c|c|c|c|c|}
\hline $\begin{array}{l}\text { Session date } \\
\text { Cashier ID }\end{array}$ & $\begin{array}{l}\text { Theatre } \\
\text { Cash } \\
\text { Check } \\
\text { Total }\end{array}$ & Bank rec. \# & \multicolumn{2}{|c|}{$\begin{array}{l}\text { Cash, non E-checks, } \\
\text { Register tape and } \\
\text { deposit slip go in here }\end{array}$} \\
\hline Session date & $\begin{array}{l}\quad \text { Theatre } \\
\text { CC: } \\
\text { E-Check } \\
\text { Total }\end{array}$ & Bank rec. \# & \multicolumn{2}{|c|}{$\begin{array}{l}\text { Signed Credit card and } \\
\text { E- Check receipts go in } \\
\text { here }\end{array}$} \\
\hline \multirow{3}{*}{\multicolumn{3}{|c|}{$\begin{array}{l}\text { Make } 2 \text { register tapes showing your } \\
\text { a. Cash } \\
\text { b. Check (non Electronic) } \\
\text { c. Cash + Check } \\
\text { d. } * * \text { if no checks input " } 0 \text { " ** }\end{array}$}} & Cash & $\begin{array}{r}120 \\
* \\
120\end{array}$ \\
\hline & & & Check & $\begin{array}{r}30 \\
* \\
30 \\
\end{array}$ \\
\hline & & & Total & $\begin{array}{r}120 \\
+30 \\
* 150 \\
\end{array}$ \\
\hline
\end{tabular}

9. Fill out daily Recon log book (The RED book)

\begin{tabular}{|l|l|l|l|l|}
\hline Date & Cashier ID & Recon\# & Cash/check & CC \\
\hline
\end{tabular}

10. Log out of your Cashier ID or simply close the Wintix window This will log your account off and prevent the next person from using your account unconsciously

\section{Close out Procedures}

These steps are for those that will close the box office

1. Run the "Totals" and "Settlement" report from the Credit Card machine.

a. Push the "Reports" button. (the rightmost purple button)

b. Press "Totals Reports" or F1, machine will print out a receipt. (Leave in machine)

c. Press "Cancel" (X) to go to the main menu

d. Press more (the Leftmost purple button)

e. Input the code "NOVA" (6682)

f. Press enter to accept the settlement 
2. Create $\mathbf{2}$ Backups of the system using the backup tool within Wintix.

a. Insert floppy disk into the computer

b. Click on Tools $>$ Backup $>$ Backup

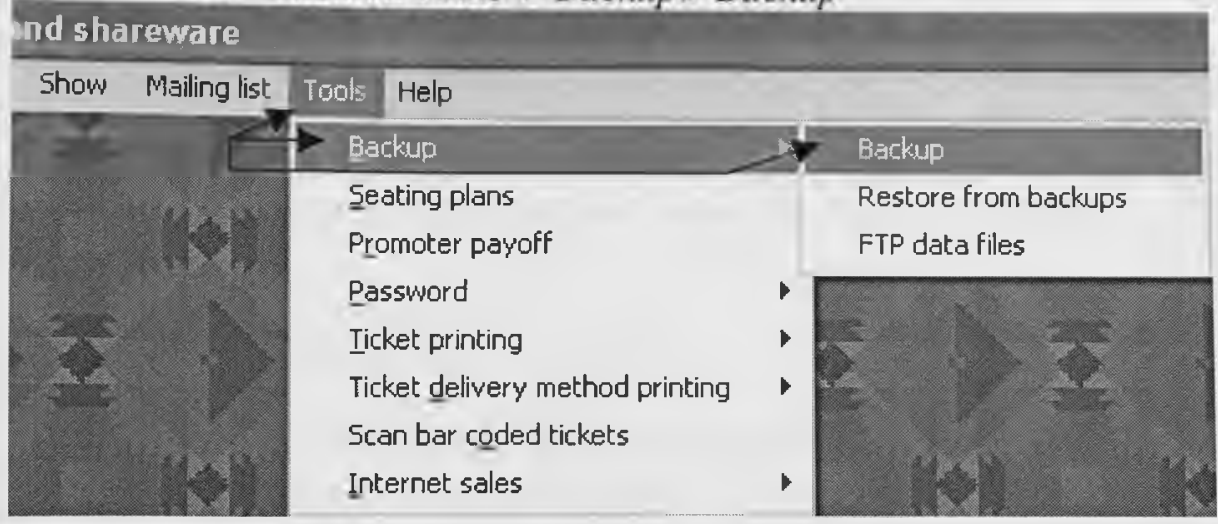

c. Select "A: $\backslash$ " (A: $\backslash$ should be default if floppy is already in) as your back up destination and click "Daily Backup"

Backing up data files

Note: This is a simple backup utility to backup the data files. It should not be construed as a

complete system backup. In particular, the EXE's, DLL's, OCX's, runtimes, and registry files

are not included

Last backup was $1 / 1 / 2007$ 12:00:00 AM

$\mathrm{A}: \mathrm{i}$

C:I

Daily backup

$P: 1$

$\mathrm{R}: \mathbf{I}$

Edit Daily.t.t

$S: 1$

c: \TIX6\0utput।

Backup everything

Edit Weekly.tut

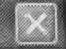

d. On the "Daily Backup" window click on "Yes" ( this confirms the data to be backed up) On the "DynaZIP ZIP Request" window click " $O K$ "

\section{DynaZIP ZIP Request}

Please insert the first disk of the Multi-Volume set.

Press OK when ready or Cancel to abort.

OK

Cancel

e. Repeat this on the second disk. 


\section{APPENDIX B.}

\section{Sample Procedures for Sound System ${ }^{20}$}

Starting up the sound system may seem very intimidating at first, but if you follow the instructions and remember to breathe deeply before attempting each step, you will not be stressed. Stressing yourself out is unnecessary, it's not a nuclear reactor, and you'll be fine. Here's the order to get the sound system up and running.

(Read instructions first, and then do)

1. Go up to the sound booth, and turn on the light. Find the circuit breaker box in the far corner and turn on breaker number 12 . This turns on the soundboard and all the equipment in the rack. It takes about 20 seconds for everything to fully turn on.

2. Now you want to turn on the amps. Let's start with the center cluster. Between the door and the rack, there is a metal box marked "C A" (looks like an electrical outlet box). You have to press the red button in; this tells the center cluster of speakers to start powering up the amps, it does everything automatically. One LED bulb lights up followed by the other. When both of the LED lights (red and green) have lit up, then you have successfully turned on the center cluster amplifiers. The process takes about 30 seconds, have patience. If nothing happens try pressing the button again.

3. Now walk back downstairs to the backstage area, catch your breath when you get there. We now need to turn on the house speakers by the audience stairs. These are the two big (self-powered) speakers sitting on top of each other, and they each need to be plugged in to work; so there are two plugs. Insert the two plugs into their own dedicated electrical boxes (behind the red curtain), look behind where each speaker is placed on stage, it should be right there. You have now turned on the main speakers to the house.

4. Next you can turn on the on-stage monitors. They are located in the racks also behind the reds (stage left and right); it doesn't hurt to turn on everything in the racks (just in case), just push in the power buttons. You have now turned on everything that you need for the sound system to work.

5. Once you have everything on, you can start plugging mics into the junction box (SR), that snakes/connects to the booth (remember the junction box 
numbers). Go back up to the booth, find the matching number on the soundboard, set that fader to "U". Make sure the little buttons for center left and right are pressed in below the fader. Then have someone talk into the stage mic. Now adjust the gain of your numbered mic left or right (very top knob), keep the level around the _ mark.

6. You may notice that you still don't have any sound coming out of the theatre's speakers, that's because when the DBX system (in the rack) started up, it automatically muted all outgoing sound signals. I have all the outputs labeled, so just locate the DBX machines (in the rack) find the center, left and right red LED buttons, and turn those little red LED's off by pressing the buttons below.

7. Now go back to the soundboard and slowly bring up and adjust your Center, Left and Right level control faders. Be careful, you may not think it sounds loud up there, but it's cranking in the house if you go past the $1 / 3$ way mark on the output LED's (you'll see them moving when sound comes out).

\section{Shutting Down:}

Bring down "ALL" fader levels on the soundboard, output and input. Turn off all the amps on both sides of the stage, turn off the center cluster by pushing the " $C$ $A$ " box next to the light switch. When the "C A" LED lights go off (both red and green) and everything is shut down on stage, then you can flip the number 12 breaker and that turns off the gear in the rack and the soundboard. All onstage amps and " $\mathrm{C} \mathrm{A}$ " box must be off before turning circuit breaker 12 off, this is a must!!! That's it, you're done. 